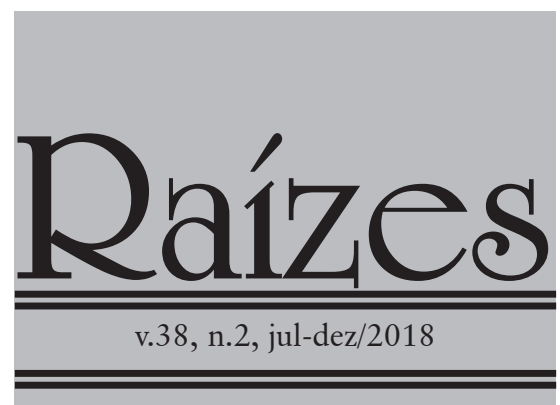

\title{
AS PRÁTICAS DAS ORGANIZAÇÕES COLETIVAS DO CAMPO EM ESPERA FELIZ/MINAS GERAIS
}

\author{
Edna Lopes Miranda ${ }^{1}$ e Ana Louise de Carvalho Fiúza ${ }^{2}$
}

\begin{abstract}
RESUMO
Este artigo tem como objetivo analisar as práticas participativas adquiridas com o envolvimento dos agricultores familiares em organizações coletivas do campo, tais como movimentos sociais ou sindicais. Todavia, o enfoque não se dá em termos das demandas coletivamente construídas e reivindicadas junto ao Estado, mas, antes, em termos daquelas práticas que se instituem na esfera da vida cotidiana. Como percurso metodológico, foram aplicados questionários semiestruturados com 72 agricultores familiares participantes das organizaçóes coletivas do campo em de Espera Feliz/MG, bem como observação participante com anotações em diário de campo nas reuniões e assembleias. Os resultados mostraram que, a participação nos ambientes de socialização das organizações coletivas do campo proporcionou aos agricultores, maiores níveis de capital político e favoreceu o desenvolvimento de suas competências para o desenvolvimento de práticas coletivas voltadas para o trabalho e a vida cotidiana, e não apenas para a sua atuação reivindicatória junto ao Estado.

Palavras-chave: Participação; Capital Político; Agricultores Familiares; Organizações Coletivas do Campo.
\end{abstract}

\section{THE PRACTICES OF THE COLLECTIVE ORGANIZATIONS OF THE FIELD OF THE MUNICIPALITY OF ESPERA FELIZ/MINAS GERAIS}

\begin{abstract}
This article aims to analyse the participatory practices acquired with the involvement of family farmers in Collective Organizations of the Field, such as associations, cooperatives and social or trade union movements. However, the focus is not on the demands collectively built and demanded from the State, but rather from those practices that are instituted in daily life. As a methodological course, semi-structured questionnaires were applied with 72 family farmers who participated in seven Collective Organizations of the Field in the municipality of Espera Feliz/ MG, as well the participant observation with notes in field diaries at meetings and assemblies. The results showed that the participation in the socialization environments of the Collective Organizations of the field, provided to the family farmers of Espera Feliz greater levels of political capital and favored the development of their competences for the development of collective practices directed for work and daily life, and not only for their claiming action with the State.

Key words: Participation; Political Capital; Small Agriculturists; Collective Field Organizations.

${ }^{1}$ Doutora em Extensão Rural pela Universidade Federal de Viçosa (UFV), MG. Membro do Grupo de Estudos Rurais, Agriculturas e Ruralidades - GERAR. E-mail: edna.miranda04@hotmail.com

${ }^{2}$ Doutora em Ciências Sociais (CPDA/UFRRJ). Coordenadora do Grupo de Estudos Rurais, Agriculturas e Ruralidades - GERAR. Professora do Departamento de Economia Rural e do Programa de Pós-Graduação em Economia Doméstica na Universidade Federal de Viçosa. E-mail: louisefiuza@ufv.br
\end{abstract}




\section{INTRODUÇÃO}

A interpretação acerca da concepção de participação política tem apresentado dissonâncias tanto em termos das discussões teóricas, que defendem o desenvolvimento da democracia pelo aprofundamento da participação, quanto por correntes que apontam as deficiências crescentes dos poderes públicos no atendimento às necessidades sociais. Observa-se que a concepção de práticas participativas encontra-se em um campo de disputa interpretativa em que novas abordagens desafiam as já estabelecidas. No que diz respeito a esse debate, na literatura brasileira nota-se a associação à dimensão institucional do processo participativo (Dagnino, 2004; Dagnino; Tatagiba, 2007). Predomina nas pesquisas nacionais, o relato de experiências participativas vinculadas a instituições criadas pelo Estado para atender às demandas da sociedade. No tocante, aos agricultores familiares, tais pesquisas confirmam esse formato, enfocando as análises, prioritariamente, nos processos de participação vinculados às práticas reivindicatórias e de enfrentamento instituídas junto ao poder público.

Em decorrência desse quadro, quase não se descortinam perspectivas, que extrapolem o âmbito reivindicatório e combativo das demandas e enfrentamentos construídos coletivamente. Neste sentido, buscou-se analisar a participação, vislumbrando o seu potencial de empoderamento em termos de práticas coletivas que se instituam no âmbito do trabalho e da vida comunitária. No entanto, não se nega as abordagens voltadas para a análise da construção de processos participativos materializados em estratégias reivindicatórias junto ao Estado. Antes, buscou-se, analisar de que forma o capital político e o perfil participativo dos agricultores familiares participantes das organizações coletivas do campo ${ }^{3}$, no município de Espera Feliz/MG se materializa em outros âmbitos da vida, como na esfera do trabalho, do mercado e da vida cotidiana. Reconhece-se, assim, que a participação em organizações coletivas, se constitui em uma prática decisiva para o fortalecimento das instituições políticas e democráticas. A escolha do foco analítico voltado para as práticas de vida dos agricultores participantes de organizações coletivas do campo deve-se ao fato de um dos grandes desafios da democracia moderna, na atualidade, consistir em consolidar práticas democráticas no âmbito microssocial, como na esfera do trabalho e da vida comunitária. Portanto, a perspectiva de análise utilizada neste artigo, enfatiza as repercussões da participação dos agricultores familiares nessas organizações, no âmbito das suas práticas de trabalho e de vida. Parte-se do pressuposto de que, o processo participativo pode criar condições para a conquista de direitos civis e sociais, que partilhados em fóruns coletivos, voltam-se para a consolidação de práticas reflexivas na vida cotidiana dos agricultores.

\section{A TEORIA DA PRÁTICA DE BOURDIEU: HABITUS, CAMPO E CAPITAL}

A teoria sociológica de Bourdieu (1980) aponta que os capitais disponíveis para os indivíduos dependem das propriedades históricas dos campos e do que está em jogo, desde que os agentes estejam imbuídos de um sistema de disposições que o autor chamou de habitus. Dessa forma, o campo se define como o espaço social onde encontram legitimidade para efetivar suas práticas. O campo político é um universo social de poder, capital, relações de força, estratégias e manutenção das ações de forças já instituídas, dotado de leis próprias de operação e de um singular tipo de capital, ou seja, capital político.

${ }^{3}$ A utilização do termo "organizações coletivas do campo" pode ser entendido na concepção de Singer (1999), como um "novo cooperativismo", capaz de mostrar o caráter diferenciado das experiências estudadas (organizações, cooperativas e associações) que podem trazer aspectos positivos para o campo dos estudos rurais. 
Os estudos de Bourdieu (1986) mostram a importância desse tipo de capital ao constatar que nem todas as oportunidades no acesso a bens e serviços podem ser diretamente relacionadas ao capital cultural e escolar dos indivíduos, pois também está em jogo o capital político, cuja distribuição é desigual e está presente nos modos de vida dos indivíduos como uma forma de apropriação privada de bens e serviços públicos. Em Bourdieu (1986), fica evidente a construção de uma rede de relações que são utilizadas pelos agentes em função do capital econômico e cultural. Esta concepção dá condições para que o capital social possa ser ativado, o que contraria as idéias de Putnam (2006), para quem "os estoques de capital social, como confiança, normas e sistemas de participação tendem a ser cumulativos e a reforçar-se mutuamente” (p.186). Nessa perspectiva, um desenvolvimento virtuoso seria o resultado de altos índices de cooperação, confiança e reciprocidade, que construídos a partir da capacidade de organização da sociedade, busca-se alcançar o bem-estar coletivo. Acredita-se que, a existência do capital social pode ser um indicador do capital político, das relações de confiança e da existência de objetivos comuns, nos processos de organização e mobilização social por parte das organizações coletivas.

O capital político está presente na formação de grupos que procuram obter êxito em suas ações por meio da cooperação e pode ser definido pela sua função, ou seja, não é uma entidade simples, mas uma variedade de diferentes entidades que torna possível a realização de certos fins que na sua ausência não seriam possíveis. Assim como a Teoria da Prática, o aporte da Teoria dos Campos Sociais de Bourdieu $(1980$; 1986) traz como argumento central a perspectiva relacional para caracterizar o tipo de capital político e o perfil participativo dos agricultores familiares nas organizações coletivas do campo. A utilização do modo relacional para se pensar o espaço social, permite analisar o tipo de capital e a posição de cada ator em relação a outro ator dentro do campo, o que proporciona compreender as estratégias utilizadas para conservação ou transformação desse campo. Dessa forma, o campo só existe porque são os agentes que criam o espaço por meio de relações objetivas e das suas disposições, em uma estrutura de relações objetivas que definem o que eles podem e o que não podem fazer. Entende-se, pelo conceito de campo, o lócus “[...] onde se trava uma luta concorrencial entre os atores em torno dos interesses específicos que caracteriza a área em questão” (Ortiz, 1994, p. 19).

Esse espaço tem na sua peculiaridade a manifestação de poder a partir de uma estrutura desigual de posições que determina um campo de dominados e dominantes. Ainda pode ser compreendido por relações de forças entre diferentes tipos de capital - mais precisamente entre agentes que possuem diferenças econômicas e simbólicas. Logo, as estratégias e mecanismos utilizados pelos agentes envolvidos dependem da situação que ocupam na estrutura do campo e na apropriação do seu capital específico. Esses princípios são invariantes e dependentes entre si, pois não se pode compreender campo sem entender as posições dos atores e não se podem compreender as posições dos atores sem explicar a forma como os diferentes tipos de capitais estão distribuídos entre eles.

Segundo Ortiz (1994), o campo político organiza-se por patamares, portanto, se as perspectivas são de alcançar os patamares mais elevados, é necessário ter capital e ampliá-lo. Essa dinâmica pressupõe, além do poder efetivo dos atores políticos, a sua visibilidade e aceitação no campo político. Desse modo, os diferentes sujeitos disputam o acesso às posições dominantes no interior do campo, por meio da valorização de seus atributos em detrimento dos atributos de seus concorrentes. O capital político também favorece o desenvolvimento de uma análise a respeito das práticas e ações desempenhadas pelos atores sociais dentro do campo político das organizações coletivas do campo. Tais relações pressupõem uma reciprocidade entre os participantes, seja mediada pela identidade ideológica, seja pelas afetividades ou pelas relações de confiança. Desta forma, a mobilização coletiva das organizações está ligadas a processos de 
ação coletiva e de inovação institucional, que como comenta Sabourin (2009), são mobilizadas para participar da elaboração de projetos de desenvolvimento local e territorial.

Conforme essa perspectiva teórica pode-se pressupor que o capital político construído por meio da participação dos agricultores familiares nas organizações coletivas do campo, repercute em práticas reflexivas sobre o cotidiano de trabalho no âmbito da agricultura familiar. Estas práticas por sua vez, implicam no envolvimento dos agricultores em vários tipos de atividades no interior destas organizações, as quais, em si mesmas, já inserem os participantes em um novo processo de socialização, marcado pelo pensamento problematizador diante da realidade vivenciada. Diante deste cenário, estes novos modelos de reflexão podem, então, entrar em contato com os modelos tradicionais e corriqueiros de comportamento e ação desenvolvidos no cotidiano desses agricultores, que são imbuídos por um capital político.

Como toda forma de capital, o capital político está desigualmente distribuído na sociedade. De posse da teoria bourdieusiana, é possível elaborar, a partir de suas categorias, uma divisão tríplice das espécies de capital político: pessoal, delegação e convertido. O capital político pessoal é baseado na ideia de ser "conhecido e reconhecido" pela posse de notoriedade e popularidade. Ou seja, como um capital político pessoal notável, resultado de um lento e contínuo processo de aprendizagem e acumulação de experiência, como ocorre com os agricultores familiares que participam das organizações coletivas do campo. Já o capital delegado trata-se de um capital detido e controlado pelas instituições que marca a transmissão de um capital político em um campo de disputa. Nessa espécie de capital, a sua natureza política é depositária de um capital que pertence, na verdade, à organização. O capital convertido se caracteriza pela conversão de outros tipos de capitais (econômico e cultural) para o campo da política, ou seja, essa conversão se efetua quando a notoriedade e a popularidade obtidas em outras áreas são transferidas para a política.

Ao participarem das organizações coletivas do campo, os agricultores passam por um novo processo de socialização, que se constitui em uma forma de conectar os indivíduos a grupos, que extrapolam o seu círculo de relações mais próximo, na família e na comunidade, proporcionando-lhes vias de acesso a novas informações e recursos. Assim, podem-se gerar, no cotidiano da vida e do trabalho dos agricultores familiares, novas práticas de adaptação e/ou resistência aos desafios que enfrentam para a reprodução social das suas unidades produtivas familiares. De posse desta perspectiva, adaptar-se pode ser entendido como um sinal de proatividade e resiliência dos agricultores aos imperativos do sistema capitalista de produção. Portanto, é nessa cotidianidade que os agricultores familiares desenham suas ações e conformam suas práticas sociais mais localizadas, traçadas no ambiente do trabalho e da vida familiar e comunitária, estabelecendo estratégias que extrapolam seus locais vividos. Segundo Simões (2005); Warschauer (2006) e Simões e Las Heras (2011), cada indivíduo, ao se articular com outros indivíduos, seja por meio de redes de comunicação ou de uma organização coletiva materializada - institucionalizada ou não - já carrega consigo algum tipo e acúmulo de capital político, entendido aqui como um capital simbólico que confere ao participante legitimidade necessária à sua ação dentro do campo. Assim, o ambiente das organizações coletivas do campo pode fornecer importantes ferramentas sobre o tipo e a forma com que está se constituindo o capital político no interior de pequenos municípios, ao analisar, especificamente, a cultura participativa dos agricultores familiares.

\section{METODOLOGIA}

Para alcançar o objetivo de analisar as práticas que se instituem na esfera da vida cotidiana, ou seja, no âmbito do trabalho, do mercado e da vida da comunidade, em decorrência da participação dos agricultores familiares em organizações coletivas do campo, tais como movi- 
mentos sociais ou sindicais, utilizou-se como estratégia metodológica a aplicação de questionário semiestruturado junto aos agricultores que participavam das organizações existentes em Espera Feliz. Utilizou-se, ainda, da técnica de observação participante em reuniões e assembleias com anotações em diário de campo. O principal critério para a escolha do município, foi a diversidade e expressividades das organizações nele existentes: associações, cooperativas, movimentos sociais, sindicatos, dentre outras instituições que expressavam diversidade de formas participativas dentro do campo da agricultura familiar. Esse município tem como parte de sua história a capacidade de mobilização da sociedade civil, ancoradas na ação das pastorais sociais da Igreja Católica, que contribuíram para a formação de organizações não governamentais com foco no desenvolvimento alternativo da agricultura familiar (Freitas; Freitas, 2013).

Inicialmente, mapearam-se sete organizações em Espera Feliz: o Sindicato dos Trabalhadores Rurais (STR); a Associação Intermunicipal da Agricultura Familiar (Asimaf); o Movimento dos Pequenos Agricultores familiares (MPA); a Pastoral da Juventude Rural (PJR); a Cooperativa de Produção da Agricultura Familiar e Solidária (Coofeliz); a Cooperativa de Crédito da Agricultura Familiar e Economia Solidária (Ecosol); e a Associação dos Terapeutas homeopatas (Terravida). A opção por pesquisar todas as sete organizações se deu em função da afinidade ideológica existente entre elas, ou seja, pelo fato das mesmas compartilharem de um mesmo campo de valores, condutas e conhecimentos que alimentam e dão suporte ao processo organizativo, principalmente no que tange á comercialização de alimentos em feiras locais e outros mercados institucionais. $\mathrm{O}$ universo da pesquisa foi composto por agricultores familiares cadastrados, totalizando 118 agricultores. Desses, 72 eram assíduos nas atividades desenvolvidas pelas organizações, o que definiu o quantitativo de agricultores familiares entrevistados. Para melhor captar a realidade investigada, optou-se por: i) caracterizar o capital político dos agricultores familiares, considerando o envolvimento nas atividades desenvolvidas pelas organizações; e ii) traçar o perfil participativo destes agricultores familiares.

Para caracterizar o capital político apropriado pelos agricultores familiares participantes das organizações coletivas do campo utilizou-se, neste estudo, uma tipologia que desagrega a classificação dos tipos de capital político propostos por Bourdieu (1986). Ressalta-se que, a ideia de "tipo" adotada remete à acepção weberiana dos tipos ideais ${ }^{4}$ (Weber, 2004), em função de se assumir como premissa que o capital político que se forja a partir da participação dos agricultores familiares nessas organizações se manifesta em intensidades e formas diferenciadas. A depender do campo político que o agricultor familiar se localiza dentro das organizações, ele pode adquirir tipos específicos de capitais e perfis participativos distintos.

Por isso, para identificar as características do capital político adquirido pelos agricultores familiares, consideramos como variável de análise o nível de engajamento nas práticas cotidianas das organizações, respaldada por uma tipologia que abarca três tipos de capital político: a) capital familiar, ou seja, aquele que tem a sua origem em uma família que possui tradição e envolvimento político em organizações e instituições da sociedade civil; b) capital conservador, compreendido como aquele que tem a sua origem na reafirmação das tradições e costumes dos agricultores familiares, não acarretando mudanças em suas práticas cotidianas; e c) capital crítico e reflexivo, construído e mobilizado pelos agricultores para o alcance de suas demandas. Neste corolário, este tipo de capital se tornou produto e reprodutor das formas de percepção social dos agricultores, na qual tende a ter um caráter reivindicatório e contestatório da realidade, como na Figura 1.

\footnotetext{
${ }^{4}$ Para compreender o sentido da ação, Weber (2004) estabeleceu o método de interpretação da realidade social e criou a noção do tipo ideal utilizado não como sentido normativo, mas como uma referência, uma construção analítica para entender sentidos complexos pelo qual serão acessadas as representações.
} 
Figura 1 - Tipos de capital político e suas características de acordo com práticas cotidianas dos participantes das organizações coletivas do campo.

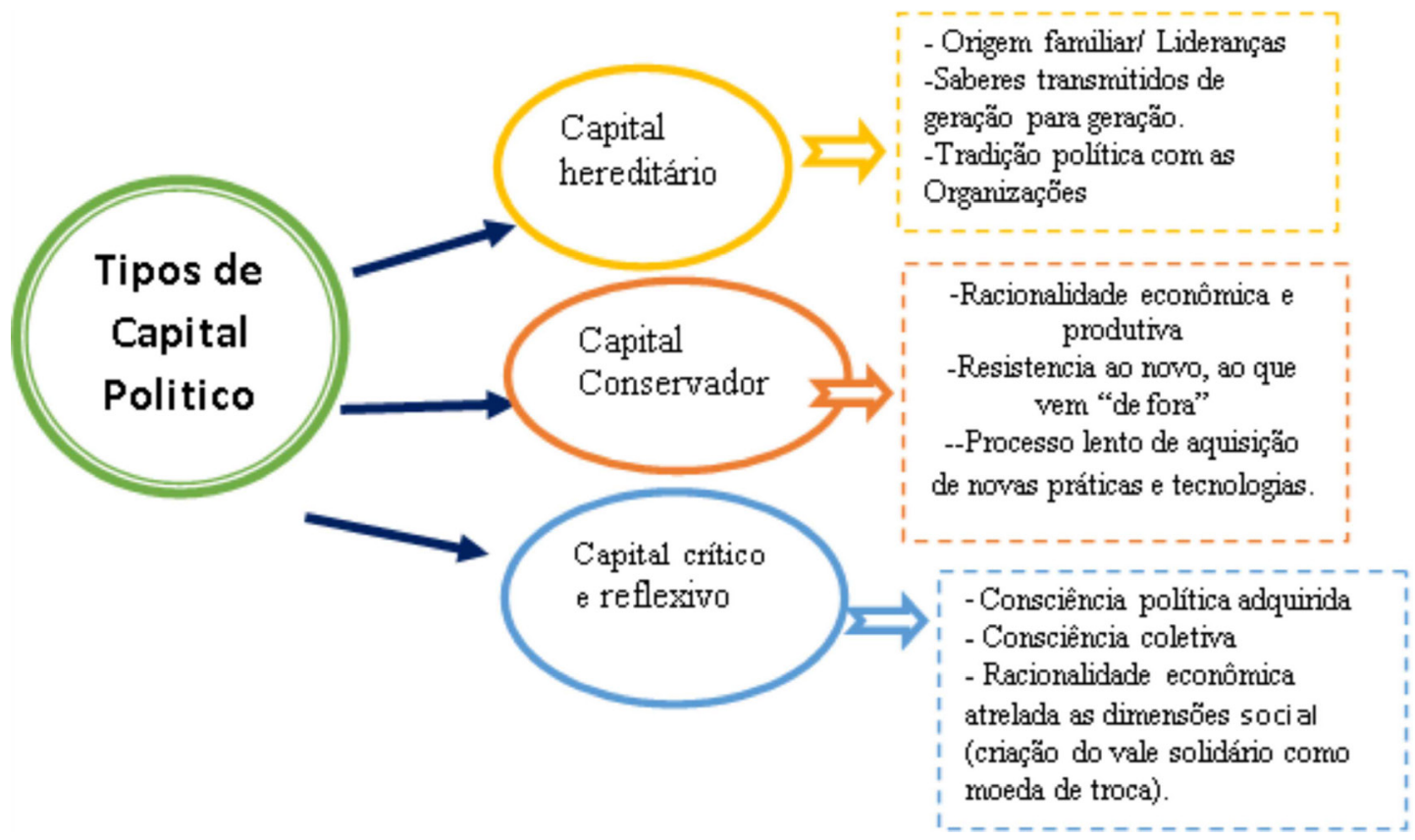

Fonte: Elaborado pela autora, 2016.

A classificação em qualquer uma das tipologias não significa que o capital político seja puro. Ao contrário, na maior parte das vezes, observa-se uma composição com pesos e medidas diferentes de cada um deles. Para a análise do perfil participativo dos agricultores familiares dentro das organizações coletivas do campo, categorizou-se o tipo de envolvimento dos agricultores familiares nas atividades desenvolvidas dentro das organizações, como assembleias, reuniões e dias de campo. Considerando a experiência dos agricultores nas práticas cotidianas das Organizações, utilizou-se as "categorias nativas" por eles próprios utilizadas para diferenciar o seu nível de envolvimento e participação: $1^{\circ}$ grupo: agricultores "participativos", apresentaram frequência regular às reuniões, assembleias e atividades voltadas para o funcionamento da organização (administração de recursos financeiros e humanos); $2^{\circ}$ ) grupo: agricultores "acomodados", participaram ocasionalmente às reuniões, mantendo um vínculo mais formal às organizações que estavam associados e $3^{\circ}$ ) grupo: "não participativos”, não participaram das atividades das organizações em nenhum momento. A partir das respostas obtidas junto aos agricultores, elaborou-se uma caracterização do capital político, considerando o grau de participação nas organizações.

\section{RESULTADOS E DISCUSSÕES}

\subsection{Histórico das organizações coletivas do campo no município de Espera Feliz/MG}

O surgimento das organizações coletivas do campo no município de Espera Feliz/MG iniciou na década de 1980, quando emergiram, no Estado de Minas Gerais, várias experiências cooperativas no âmbito da agricultura familiar. Essas organizações realizavam as suas atividades dentro do plano de desenvolvimento local denominado "Envolvimento Local" (ELO). Tratava-se de um plano de ação iniciado em 2004, que promoveu várias discussões. Foi implementado na forma de um colegiado, no qual várias organizações coletivas buscavam elaborar estratégias de ação de forma conjunta com vistas a promover o desenvolvimento local (Silva, 2010, Freitas; Freitas, 2013). 
Dentre as organizações coletivas do campo de Espera Feliz, a que se mostrou mais importante em congregar os agricultores familiares - enquanto atores políticos da agricultura familiar na região - foi o Sindicato dos Trabalhadores Rurais (STR). A sua trajetória histórica pode ser dividida em duas fases: uma marcada pela ação das Comunidades Eclesiais de Base (CEB), que propunham formar lideranças com uma orientação mais atuante frente aos conflitos agrários no Brasil; e a segunda, que se caracterizou pelo surgimento de parcerias com outras organizações com o objetivo de promover a agroecologia e a economia solidária no município, além de inserir nas práticas das organizações coletivas, questões produtivas, de comercialização, de crédito, entre outras.

Tal processo levou à consolidação de várias organizações ligadas diretamente ao Sindicato, tal como: a Associação Intermunicipal da Agricultura Familiar (Asimaf), que era responsável pela organização política dos agricultores familiares em suas atividades de comercialização. Porém, com as modificações do Código Civil a partir de 2002, as associações ficaram impossibilitadas de comercializarem seus produtos. Como resposta a esta situação, os agricultores se mobilizaram via Sindicato dos Trabalhadores e, em 2005, criaram a Cooperativa de Produção da Agricultura Familiar de Espera Feliz (Coofeliz), no intuito de desenvolver atividades voltadas à comercialização de alimentos (Silva, 2010).

Diante deste cenário, o principal mercado para as organizações existentes no município foram as políticas públicas de compras governamentais: o PAA e o PNAE, acessadas pelos agricultores através da cooperativa Coofeliz. O PAA é popularmente conhecido entre os agricultores familiares como "Programa da CONAB" (Companhia Nacional de Abastecimento). No munícipio de Espera Feliz, Minas Gerais, o Programa de Aquisição de Alimentos (PAA), teve início em 2004, mas foi somente em 2006 que a Coofeliz passou a operacionalizar o programa, com o objetivo de fortalecer os circuitos locais e regionais. Já o PNAE é denominado pelos agricultores de "Programa dos trinta por cento" ou de "merenda escolar". Ele foi implantado em 2009, em decorrência da exigência de compra da agricultura familiar pela Lei n. ${ }^{0} 11.947$, que definiu que pelo menos 30\% dos recursos financeiros da alimentação escolar deveria ser da agricultura familiar. Embora estes dois programas tenham trajetórias distintas, Belik e Domene (2012), apontam que, ambos apresentam como denominador comum a compra institucional local de produtos da agricultura familiar para ações de segurança alimentar e nutricional.

Como consequência de uma série de mobilizações sociais iniciadas em 2002 e os desdobramentos do movimento político da agricultura familiar no município, surgiu, também, a Ecosol. Esta Cooperativa passou a desenvolver mecanismos de controle social do crédito, aproveitando as potencialidades das organizações de base, com o trabalho efetivo nas comunidades. Também atua nessa direção a Pastoral da Juventude Rural (PJR), buscando inserir os jovens rurais nas organizações coletivas do campo, com a colaboração do Movimento dos Pequenos Agricultores (MPA). Esse, por sua vez, compartilha dos princípios e objetivos da Associação dos Terapeutas Homeopatas (Terravida), comungando do princípio da não utilização de produtos químicos nas lavouras e rebanhos. A história da coletividade desenvolvida pelas organizações coletivas em Espera Feliz e suas formas pregressas com os trabalhos das Comunidades Eclesiais de Base (CEBs), grupos ligados à Igreja Católica, fez emergir uma das formas mais recentes destas organizações: um arranjo organizacional cooperativo, que pode ser entendido nos moldes de um capital político contemporâneo, capaz de potencializar a mobilização de recursos, pessoas e ações para uma proposta compartilhada de transformação da realidade social e econômica da agricultura familiar na região. 
3.2 A participação dos agricultores familiares nas atividades das organizações coletivas do campo

Os dados coletados na pesquisa evidenciaram a existência de diferenças significativas quanto à natureza da participação dos agricultores nas atividades promovidas pelas organizações coletivas do campo no município de Espera Feliz, tanto no que se refere à "forma" quanto à "intensidade". Observou-se, por meio dos questionários, que, no geral, os agricultores familiares participavam de mais de uma Organização Coletiva: 52\% do Sindicato e 46\% de Cooperativas e Movimentos Sociais. No que diz respeito ao sindicato, cabe destacar que dele se desdobraram outras organizações, com as quais ele mantém uma rede de relações e parcerias. De modo complementar, seria pertinente destacar a afirmação de Putnam (2006) para quem a existência de redes permitiria adquirir confiança, traduzida na aceitação e observância de normas, que provocaria um círculo virtuoso da cidadania, por meio da reciprocidade entre os indivíduos que interagem dentro da rede de organizações.

Os dados da pesquisa de campo revelaram que, ao serem inquiridos sobre a importância das organizações em Espera Feliz, a maioria dos agricultores familiares apontaram que a representatividade delas se fazia importante, na medida em que possibilitavam a troca de informações e a implantação de serviços indispensáveis à qualidade de vida das populações rurais, como mostra a seguir:

Tabela 1 - Avaliação quanto à correspondência das ações desenvolvidas nas organizações de Espera Feliz face às necessidades dos agricultores familiares

\begin{tabular}{ll}
\hline Atendimento as demandas & $\begin{array}{l}\text { Frequência } \\
\%\end{array}$ \\
\hline Muitas vezes & 82 \\
Algumas vezes & 10 \\
Raramente & 8 \\
Nunca & 0 \\
\hline
\end{tabular}

Fonte: Trabalho de campo, 2016.

De acordo com a Tabela 1, mais de $80 \%$ dos agricultores familiares apontaram que as ações desenvolvidas nas Organizações Coletivas na qual participavam “muitas vezes” estavam em consonância com as suas necessidades. Contudo, é fundamental considerar que as necessidades e os interesses manifestados pelos agricultores podem ser dissonantes. Daí a opção teórica por se considerar o espaço das organizações coletivas como um campo político de disputas de poder, posição e acesso a diferentes capitais, no qual as condutas dos agentes são determinadas por sua posição na estrutura da relação de forças desse campo (Bourdieu, 1986). Nesse sentido, observou-se uma situação ocorrida durante uma plenária, na qual um dos agricultores se queixou de sempre serem os mesmos agricultores que atuam "na linha de frente" das organizações, mantendo-se os outros “acomodados", em função de terem sempre alguém responsável por executar as tarefas. Esse descontentamento apontou para uma distribuição diferenciada do capital político entre os agricultores familiares, a qual denota, em consequência, uma capacidade de ação diferenciada entre eles. Por outro lado, ter esse espaço e ter voz para reclamação possibilitou a construção de possibilidades de participação nas organizações.

Se pensarmos nos aspectos normativos da legislação, as associações e cooperativas deveriam ser construídas coletivamente com lógicas de participação democrática, uma vez que todos os cooperados fazem parte de uma mesma organização.

No entanto, em seu estudo, Cruz (2007) mostrou que há muitas dificuldades nesse imperativo e destacou que "a simples existência de um número razoável de associações não signi- 
fica necessariamente que haja relações mútuas de confiança ou que as relações sejam baseadas na cooperação social” (p. 98). Desta forma, para que o associativismo seja efetivo e contribua para o desenvolvimento da sociedade local, salienta-se que aconteça o engajamento e o espírito cooperativo de todos os membros

Conforme os resultados, para além de eventuais descontentamentos entre os agricultores, há muitos interesses que os unem, visto que não foram observadas reclamações relativas ao percentual de contribuição para a manutenção das organizações coletivas. Depreende-se, assim, que a participação dos agricultores familiares nas organizações se sustenta em termos de interesses coletivos organicamente legitimados.

É perceptível entre os agricultores participantes das organizações coletivas uma orientação pelos costumes e concepções das organizações de realizarem conjuntamente as suas atividades a partir das necessidades identificadas. Ou seja, as ações desenvolvidas por essas organizações, buscam priorizar as necessidades emergenciais. Dessa forma, as iniciativas empreendidas pelos agricultores dentro das organizações propiciam ações voltadas para os interesses hegemônicos no grupo, que se sustentam em decorrência da corresponsabilização dos participantes nas ações executadas.

Entre os motivos expressos pelos agricultores familiares para sua participação nas organizações coletivas percebeu-se a força da perspectiva que vislumbra a necessidade de lutar em prol de questões coletivas, expressa no Gráfico 1.

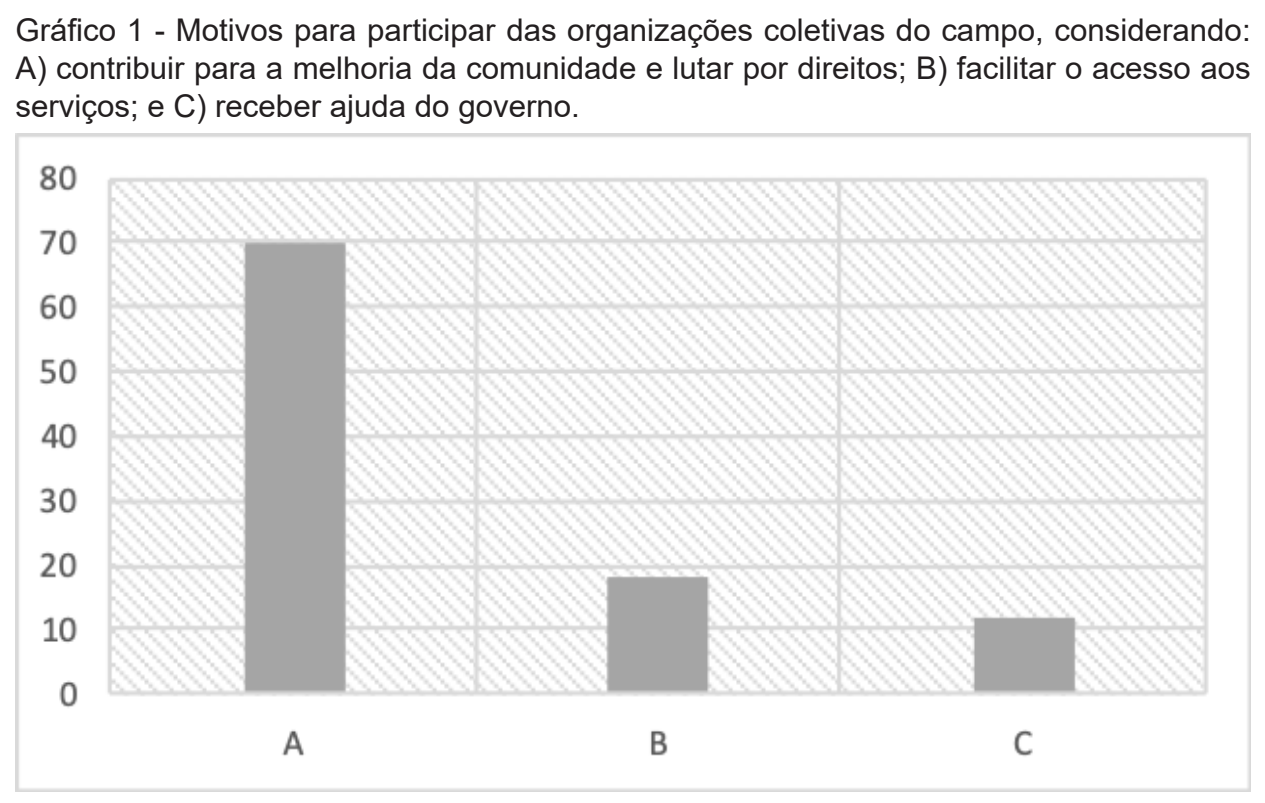

Fonte: Trabalho de campo, 2016.

Uma parcela significativa dos agricultores (80\%), afirmaram que um dos motivos para participar das organizações foi a vontade de contribuir com a comunidade e lutar por direitos, buscando melhorias e colaborando com o crescimento dela. Foi recorrente, também, a revelação de que, por meio das Organizações Coletivas tiveram melhores condições de acesso a serviços (15\%). Percebe-se, assim, que essas organizações eram vistas pelos agricultores participantes como geradoras ou facilitadoras do acesso a recursos e, eventualmente, conversíveis em capital econômico e oportunidades sociais. Entre as vantagens, os agricultores destacaram o acesso às linhas de crédito, aos programas de governo como, o Programa de Aquisição de Alimentos (PAA) e o Programa Nacional de Alimentação Escolar (PNAE), o fornecimento e distribuição de sementes e equipamentos agrícolas, a promoção de cadeias curtas para a comercialização dos alimentos, a troca de informações e o acesso à aposentadoria rural. De acordo com os agricultores, estas políticas recentes de compras governamentais de produtos da agricultura fa- 
miliar, trouxeram oportunidades significativas para viabilidade econômica da produção, mas também muitos desafios para atender ao mercado institucional, uma vez que necessitaram fazer o planejamento e organização adequada da produção, através de uma gestão eficiente dos recursos, ou seja, precisaram ter um a visão mais empreendedora dos recursos disponíveis.

Embora os agricultores entrevistados, tenham ressaltado dificuldades para acessar estas políticas, como por exemplo, a adequação ás questões sanitárias e de assistência técnica, ainda sim, o PNAE continua sendo a política pública mais acessada. Ressaltaram também, o quão significativo têm sido as ações do mercado institucional de alimentos na melhoria das condições de vida das famílias. Isso pode ser percebido na dimensão econômica, com o aumento da renda e diversificação da produção; na dimensão social, com o fortalecimento das organizações e participação da mulher e dos jovens dentro do arranjo institucional; no plano ambiental, através de práticas sustentáveis de respeito ao meio ambiente e produção livre de agrotóxico. Além disso, vale ressaltar a questão da segurança alimentar, na qual estes programas têm contribuído para ampliar o repertório alimentar das famílias. Estes achados da pesquisa corroboraram com o caso pesquisado por Cunha et al (2015), que ao estudar os reflexos dos programas governamentais de aquisição de alimentos (PAA e PNAE) na agricultura familiar de Espera Feliz, constatou que, os dois programas possibilitaram a diversificação da produção e aumento da renda dos agricultores, o que consequentemente promoveu uma maior participação de mulheres e jovens nas organizações, a adoção de práticas sustentáveis e a defesa da segurança alimentar com melhoria da saúde das famílias dos agricultores.

Neste cenário, segundo os agricultores participantes, a organização coletiva se torna, por vezes, o único canal e o mais confiável meio de interlocução com os setores de gestão pública. Para Souza (1995), os fluxos de informação horizontalizadas por meio de vias associativas costumam ser mais confiáveis que de categorias verticalizadas, visto que os menos favorecidos podem compreender melhor as informações.

Deduz-se que, o grau de participação dos agricultores nas organizações coletivas do campo pesquisadas, tem estreita relação da atuação delas com seus interesses, tanto individuais, quanto coletivos. Nas experiências associativas vivenciadas no município de Espera Feliz, notou-se a existência de princípios democráticos baseados em ações intencionais, que almejavam melhores condições de vida para os agricultores familiares. Putnam (2006) já destacava como o engajamento da coletividade era fundamental para o desenvolvimento de uma comunidade, muito mais que a ação dos órgãos governamentais somente.

3.3 Caracterização do capital político dos agricultores familiares participantes das Organizações.

Quanto á origem do capital político adquirido pelos agricultores familiares, os resultados apontaram que, $75 \%$ dos 72 agricultores familiares participantes das organizações -57 agricultores - começaram a sua militância ainda quando jovens, o que lhes permitiu conquistar posições no interior dos movimentos sociais, associações e sindicatos, adquirindo, assim, o que se pode chamar de habitus político. Para o restante dos agricultores participantes (25\%), o envolvimento em Organizações teve como principal motivo a participação de algum membro da família nas atividades desenvolvidas por elas, como reuniões, assembleias, encontros e eventos festivos. Portanto, para esses agricultores familiares, essa forma tradicional de participação política constituiu-se na principal porta de acesso as essas organizações.

Ao ingressar no campo político das organizações há normas e regras de funcionamento que precisam ser obedecidas e que regem a ação coletiva dos agricultores. Assim, a aderência 
dos indivíduos às ideias, comportamentos e regras das organizações coletivas não depende exclusivamente das preferências pessoais dos envolvidos, mas requer uma negociação. Dessa forma, o desenvolvimento de competências e de negociação coletiva já se colocou desde o âmbito do funcionamento.

Os estudos de Bordenave (1986), Demo (1996), Bava (2004) e Brose (2004) apontam para o fato de que a participação em organizações coletivas pode contribuir para que o cidadão ou grupo perceba com mais clareza os demais cidadãos ou grupos sociais. Acrescenta-se, ainda que, por seu caráter cooperativo, tende a romper modelos de relações autoritárias, inserindo os indivíduos em outros patamares de cidadania política. No entanto, a participação de qualidade requer que as pessoas aprendam a participar, que desenvolvam a sua capacidade de comunicação interpessoal. Uma das respostas permite ilustrar isso: “Quando o povo assume o compromisso de participar ele participa mesmo. Todos nós conversamos, participamos das atividades, contamos umas piadas e se tem alguma dúvida, um fala para o outro, mas às vezes muitos não estão dispostos a participar de tudo" (E3). Contudo, como afirma Costa (2004), o fato de os indivíduos estarem em um grupo não significa que haverá entre eles uma sinergia de ideias.

Ainda para Sabourin (2009), é preciso que as normas sejam integralizadas no grupo, a fim de que haja cooperação e comprometimento com os objetivos traçados. Ao serem perguntados se costumam discutir os problemas enfrentados pela comunidade nas Organizações, 90\% dos entrevistados relataram haver uma inclinação para o debate, no qual todos os participantes discutiam o problema e decidiam em conjunto a melhor solução a se tomar, apontando para a presença de uma cultura política e participativa. Ademais, para estes agricultores, o incentivo às relações de reciprocidade entre os agricultores com a comunidade, as redes de proximidade e o encurtamento das cadeias de produção, permitiram aos agricultores mecanismos de maior controle sobre os sistemas alimentares, proporcionando-lhes autonomia e elevando a coesão social dos participantes das organizações coletivas.

Para os agricultores familiares do município de Espera Feliz, as principais regras do jogo político no interior das organizações estavam relacionadas aos critérios para o ingresso e a permanência nas atividades desenvolvidas, que devem ser partilhados por todo o grupo, para que haja uma maior coesão social e cooperação interna. Ao buscar compreender o perfil participativo dos agricultores familiares nas sete organizações coletivas do campo, constatamos que a interação entre os agricultores ocorre especialmente por meio das situações formais no trabalho, como em reuniões, cursos e palestras. Contudo, os almoços e encontros festivos que ocorrem nas organizações denotam situações informais dentro delas. Como relatado pelos entrevistados, "as situações informais deixam os indivíduos mais à vontade para a troca e partilha de conhecimentos e experiências”. Tal relato vai ao encontro da pesquisa realizada por Onyx e Bullen (2000), que identificaram sentimentos de confiança e segurança; vínculos de família e amizade como alguns fatores que melhor definem o capital político.

Para compreender a forma como a participação política dos agricultores familiares se configurava nas organizações, realizou-se um mapeamento das práticas por eles compartilhadas. Constatou-se que as práticas agroecológicas contavam com o apoio dos agricultores no interior das organizações, uma vez que estes apresentavam, um conjunto de iniciativas que apontava para: a diversificação da produção, a preocupação com o meio ambiente, a utilização de técnicas adaptadas às condições locais e a produção de alimentos sem uso de agrotóxicos.

Em seu estudo, "Agricultores e impérios alimentares: lutas por autonomia e sustentabilidade na era da globalização”, Ploeg (2008) comenta que a luta empreendida pelo campesinato por uma maior autonomia e a reprodução de seu grupo familiar tem determinado uma forma muito particular de organização dos recursos produtivos e sua relação com o mercado. 
Os resultados mostraram as diferentes razões para participarem, tendo se destacado como principal motivo para a participação o acesso aos direitos sociais, como: educação; saúde, e melhores condições de vida para a família e a comunidade. As organizações coletivas foram percebidas como instrumento necessário para a conquista de tais direitos. Os resultados também trouxeram evidências de que a expressiva participação dos agricultores familiares nas atividades desenvolvidas pelas organizações estava associada às atividades que traziam algum benefício imediato para o participante, tais como: o acesso ao Programa Nacional de Alimentação Escolar (PNAE) e ao Programa de Aquisição de Alimentos (PAA).

Ao avaliar o impacto do Programa de Crédito do Instituto de Desenvolvimento Agropecuário (INDAP) e o ingresso de pequenos produtores agrícolas ao Programa, os pesquisadores Donoso, Melo e Negrete (2010), constataram que os agricultores que conhecem e avaliam os custos financeiros de crédito apresentaram maior disposição a participar dos processos de tomada de decisão. Esta situação revela que o acesso às políticas públicas e a busca por melhores condições de trabalho, se constitui em uma motivação racional e consciente para que os agricultores familiares participem de forma assídua das organizações coletivas. Esta realidade não é muito diferente de Espera Feliz, haja visto que, o acesso as políticas e programas governamentais têm estimulado a adesão dos agricultores ás organizações e possibilitado a participação de mulheres e jovens. Constatou-se, assim, que o processo de reconhecimento da agricultura familiar e as possibilidades de acessar as políticas públicas para a obtenção de crédito para investimento e custeio da produção, influenciaram a participação dos agricultores familiares nas organizações coletivas. Embora o acesso a essas políticas tenha contribuído para ampliar a participação dos agricultores nas organizações, os resultados mostraram também que, estes agricultores já trazem consigo uma trajetória de mobilização e histórico de participação cívica, confiança e ação coletiva para questões voltadas para a agricultura familiar. Desta forma, o empenho desses agricultores em participar de organizações sociais ultrapassa a ideia de capital político e de interesses, ao passo que tangencia questões de pertencimento, identitárias e de reprodução social como modo historicamente construído de permanência no campo.

Dentre os participantes das Organizações Coletivas, 76\% participavam de eventos formais, como reuniões, assembleias, palestras e cursos. Dentre os cursos oferecidos, foram citados com destaque os ministrados pelo Sindicato dos Trabalhadores Rurais (STR), relacionados à formação de liderança e de trocas de experiências entre os agricultores. Tais cursos capacitam os agricultores em relação a questões produtivas e de comercialização, indo ao alcance de suas reais necessidades. É o caso, por exemplo, dos agricultores que produzem café orgânico e que se inserem em discussões relativas ao comércio internacional e às possibilidades de acesso dos agricultores de menor renda aos produtos orgânicos.

De modo complementar, o Centro de Tecnologias Alternativas da Zona da Mata (CTA-ZM) e a Coofeliz têm realizado diversas reuniões entre os agricultores familiares cooperados com o objetivo de capacitá-los para produzir alimentos de qualidade e também elaborar um planejamento estratégico no processo de comercialização de alimentos da agricultura familiar para o mercado institucional, especificamente PAA e o PNAE. As possibilidades abertas pelos mercados institucionais de alimentos, têm tido grande importância para a melhoria da renda dos agricultores familiares, constituindo-se em um fator que promove uma participação genuinamente sentida pelos seus beneficiários. 
Como forma de suprir a carência de capital de giro da cooperativa e melhorar a sua atuação como intermediária entre os agricultores e os beneficiários dos alimentos, foi criado, em 2010, o Vale Solidário, uma espécie de moeda social que o agricultor recebe no ato da entrega dos produtos e depois pode sacar o dinheiro na cooperativa de crédito ou utilizá-lo em compras nos estabelecimentos comerciais de Espera Feliz. O Vale Solidário foi reconhecido pela Fundação Banco do Brasil de Tecnologia Social (FBB,2013), com o prêmio de boas práticas de tecnologia social. Segundo Buainain e Garcia (2014), ações em parceria como as realizadas pela Coofeliz são importantes para incentivar a inserção produtiva e comercial dos agricultores familiares em face das transformações recentes dos mercados.

Assim, percebe-se uma predisposição atitudinal dos agricultores familiares à execução partilhada de ações direcionadas a sua realidade local. Eles se mostram orientados por uma economia moral ou, como afirma Scott (1985), por uma ética de subsistência, que além da estratégia produtiva, pressupõe a manutenção de regras sociais baseadas em relações de reciprocidade do camponês com parentes, amigos, vizinhos e, de modo mais distanciado, com o próprio Estado. Essa ética também serve de elemento balizador das relações de trabalho do pequeno agricultor e do seu comportamento diante do contexto sociopolítico implementado.

Dentre as atividades realizadas pelas organizações no âmbito da agricultura familiar destacam-se as ações inovadoras realizadas pela Coofeliz na busca de soluções para os problemas de acesso aos mercados e àqueles referentes à degradação ambiental, como as atividades com os sistemas agroflorestais e com a cafeicultura orgânica. Tais ações desenvolvidas pelos agricultores familiares se alicerçam em uma ideologia de resistência à dependência de insumos externos, voltando-se para a construção de um modelo de desenvolvimento ambientalmente sustentável. Iniciativas como a feira agroecológica e o "mercadinho do produtor" são exemplos de ações que buscam uma maior inserção da agricultura familiar nos mercados. Mesmo com dificuldades quanto à regularidade no fornecimento de produtos e a necessidade de capital para a compra da produção da agricultura familiar, a Coofeliz tem buscado envolver os agricultores familiares em suas atividades, ao demonstrar o potencial produtivo e organizativo desses agricultores. Uma dessas alternativas foi a criação de uma marca coletiva, com o objetivo de agregar valor aos produtos comercializados. Embora a maior parte da produção comercializada pela Coofeliz seja escoada para os programas de mercado institucional (PAA e PNAE), os produtos da agricultura familiar são também colocados nos mercados locais, regionais e nas redes de consumidores $^{5}$, como a Raízes da Mata e a Rede Ecológica, com a marca CooFeliz. A oportunidade de atender a esses mercados fortaleceu as redes de comercialização de cadeias curtas. Ademais, merece destaque o aspecto social das feiras livres desenvolvidas pelas organizações coletivas do campo na região, pois, ao ofertarem produtos locais, promovem a socialização entre os agricultores e a interação face a face. A partir da análise do perfil participativo dos agricultores familiares, elaboramos a tabela abaixo:

Tabela 2 - Perfis participativos dos agricultores familiares, de acordo a participação política e envolvimento nas Organizações

\begin{tabular}{lll}
\hline Perfil Participativo & Números de participantes & Porcentagem \\
\hline Participativos & 54 & $75 \%$ \\
Acomodados & 12 & $16 \%$ \\
Não participativos & 6 & $8 \%$ \\
Total & 72 & $100 \%$ \\
\hline
\end{tabular}

Fonte: Dados da pesquisa, 2016.

${ }^{5}$ A Rede de consumidores de produtos agroecológicos/orgânicos são organizações não governamentais que visam a fomentar compras coletivas a partir de princípios ético, solidário e ecológico de agricultores familiares do Brasil. 
A categoria "participativo" correspondeu a 54 dos 72 agricultores entrevistados (75\%), que apresentaram uma trajetória de mobilização e participação em movimentos sociais, associações e sindicatos ainda quando jovem, por volta da década de 1980, o que vem a comprovar o uso desse termo no grupo. Já o termo "acomodado", designava o comportamento de 12 dos 72 agricultores entrevistados (16,6\%), caracterizando o perfil daqueles que se manifestavam como na fala a seguir:

(...) às vezes é difícil sair de casa para ir para participar das atividades realizadas pelas organizações aqui do município por conta do trabalho na roça, mas também a gente vai ficando meio acomodado e acaba não participando muito dos assuntos que são falados nas reuniões e assembleias, mas já fui em muito eventos que as organizações fazem aqui no município”. (E2).

É interessante notar que, embora os agricultores dessa categoria não tenham participação ativa nas atividades das organizações, eles revelaram que em algum momento já participaram delas e reconheceram a importância das atividades por elas desenvolvidas no desenvolvimento local.

Na categoria "não participativo", se encaixaram seis dos 72 agricultores entrevistados (8,3\%). De acordo com a fala da representante do STR, “[...] a maioria destes agricultores só aparece no sindicato com o interesse de ganhar alguma vantagem ou para se informar sobre linhas de crédito, aposentadoria rural ou coisa deste tipo e nunca se envolve com os projetos e luta por direitos sociais”. Esse grupo reflete uma racionalidade mais pragmática voltada para os seus interesses privados. No entanto, percebemos entre os agricultores entrevistados uma cultura política participativa que se instituiu de forma processual desde as mobilizações realizadas pela Igreja Católica, pelos sindicatos, movimentos sociais e outras organizações da sociedade civil que, a partir da década de 1980, passaram a atuar na formação e mobilização política dos

agricultores familiares do município de Espera Feliz, Minas Gerais. De forma similar, Barreira (2013), ao estudar as diferentes experiências participativas entre as entidades associativas e os poderes locais do estado do Ceará, notou que os mecanismos de participação social, presentes em gestões municipais, apontavam para dimensões importantes de uma "cultura política" proveniente de experiências anteriores de organização e nas redes do poder local.

\section{CONCLUSÕES}

O conjunto de dados examinados evidenciou, em primeiro lugar, que a participação dos agricultores familiares de Espera Feliz tem um caráter longevo, visto que ela foi iniciada na década de 1980, há mais de 30 anos, alcançando, assim, um caráter transgeracional. A alta participação dos agricultores familiares nas organizações coletivas do campo apontou para a organicidade delas em termos das ações desenvolvidas com as necessidades e oportunidades vislumbradas pelos agricultores familiares. O envolvimento permanente dos agricultores familiares nas atividades desenvolvidas pelas organizações indica a presença de agricultores que acreditam na participação como uma forma de buscar melhores condições de vida para si e para a comunidade.

A análise dos resultados mostrou que a participação nos ambientes de socialização das organizações coletivas do campo, proporcionou aos agricultores familiares de Espera Feliz, maiores níveis de capital político e favoreceu o desenvolvimento de suas competências coletivas, o que comprovou a hipótese de que o capital político que se forja a partir da participação dos agricultores familiares nas organizações tende a aumentar sua capacidade de reprodução social na agricultura familiar, proporcionando-lhes perspectivas sociais positivas. 
Os resultados da pesquisa ainda indicaram que, dos três grupos de agricultores mapeados segundo o seu grau de participação nas organizações coletivas do campo, os denominados como "participativos" tiveram experiências prévias de participação em movimentos sociais rurais, cooperativas e associações, que provavelmente os socializaram dentro de uma cultura políticas, capacitando-os para assumir postos de liderança nessas organizações. No extremo dessa relação, se encontravam os denominados "não participativos", que possuíam uma racionalidade pragmática voltada para a efetivação de fins palpáveis tanto no âmbito familiar como comunitário. Percebeu-se, nesse grupo, que a sua cultura participativa foi mais marcada por iniciativas coletivas que instituíam oportunidades concretas de ganhos materiais, estando ausente da sua cultura participativa a experiência de cunho combativo das décadas de 1980 e 90, construída pelos movimentos sociais, sindicatos, partidos políticos e pela Igreja.

O perfil participativo dos agricultores familiares tem um vínculo claro com os repertórios de ação anteriores, advindos das organizações com perfil mais alternativo e de resistência. Percebeu-se, no entanto, que a cultura política desenvolvida por essas organizações se flexibilizou, acompanhando o campo de oportunidades abertas pelas políticas públicas dos anos 2000, voltadas para a valorização da agricultura familiar. Diante dos resultados apresentados, percebeu-se que há um capital político favorável entre os agricultores familiares que participam das organizações, ou seja, um espírito de equipe capaz de fortalecer os grupos a obter maior legitimidade em suas ações.

\section{REFERÊNCIAS}

BAVA, S. C. Participação, representação e novas formas de diálogo público. São Paulo: Polis; Programa Gestão Pública e Cidadania/EAESP/FGV, 2001.

BARREIRA, I.A.F. Conselhos de fato e conselhos no papel: poderes locais e práticas de participação. Raízes, v.33, n.01, p.105 - 118, 2013.

BELIK, W. e DOMENE, S. M. A. Experiências de programas combinados de alimentação escolar e desenvolvimento local em São Paulo - Brasil. Revista Agroalimentária, São Paulo, v. 18, n. 34, p. 57, 2012.

BORDENAVE, J. E. D. O que é participação. 4 ed. São Paulo: Brasiliense, 1996.

BOURDIEU, P. Esboço de uma teoria da prática. In: ORTIZ, R. (org.). Pierre Bourdieu: sociologia. São Paulo: Ática, p. 46-81. Tradução de Paula Montero e Alicia Auzmendi, 1980.

. O poder simbólico. Rio de Janeiro: Bertrand Brasil; Lisboa, Portugal: Difel, 1986.

BROSE, M. (Org.). Participação na extensão rural: experiências inovadoras de desenvolvimento local. Porto Alegre: Tomo Editorial, 2004.

BUAINAIN, A. M.; GARCIA, J. R. Agricultura Familiar e Transformações Recentes do Mercado. In: DOULA, S. M. et al. A agricultura familiar em face das transformações na dinâmica recente dos mercados. Viçosa: Suprema Gráfica e Editora, 2014. p. 89-126.

COSTA, R. Inteligência afluente e ação coletiva. A expansão das redes sociais e o problema da assimetria indivíduo/grupo. Razón y Palabra, n. 41, Out/Nov 2004. Disponível em: <http://www.cem.itesm. mx/dacs/publicaciones/logos/anteriores/n41/rdacosta.html>. Acesso em: 15 fev. 2017.

CRUZ, G. dos R. Associativismo e democratização da sociedade: limites e possibilidades. Comunicação \& política, v. 24, n. 3, p. 89-114, 2007.

CUNHA, W.A da; FREITAS, A.F de; SALGADO, R.J dos S.F. Efeitos dos Programas Governamentais de Aquisição de Alimentos para a Agricultura Familiar em Espera Feliz, MG. Revista de Economia e Sociologia Rural, v. 55, n. 3, p. 427-444, set.2017. 
DAGNINO, E. Construção democrática, neoliberalismo e participação: os dilemas da confluência perversa. Política e sociedade, n. 5, p. 139-164, out. 2004.

DAGNINO, E.; TATAGIBA, L. (Orgs.). Democracia, sociedade civil e participação. Chapecó: Argos, 2007.

DEMO, P. Participação é conquista: noções de política social participativa. 3 ed. São Paulo: Cortez, 1996.

DONOSO, G.; MELO, O.; NEGRETE, E. Participation determinants and impact assessment of the Institute of Agricultural Development (INDAP) credit program. Ciencia e Investigación Agraria, Santiago, v. 37, n. 2, p. 87-99, ago. 2010.

FBB. Fundação Banco do Brasil. Prêmio Fundação Banco do Brasil: tecnologias sociais, 2013.

FREITAS, A. F.; FREITAS, A. F. Análise institucional de mudanças organizacionais em um sistema cooperativo de crédito solidário em Minas Gerais. Revista de Administração Pública, Rio de Janeiro, v. 47, n. 4, p. 999-1019, 2013.

ONYX, J.; BULLEN, P. Measuring Social Capital in Five Communities. The Journal of Applied Behavioral Science, v. 36, n. 1, p. 23-42, mar. 2000.

ORTIZ, R. Pierre Bourdieu. São Paulo: Ática, 1994.

PLOEG, J. D. V. Agricultores e impérios alimentares: lutas por autonomia e sustentabilidade na era da globalização. Porto Alegre: Editora UFRGS, 2008.

PUTNAM, R. Comunidade e democracia. A experiência da Itália moderna.5 eds. Rio de Janeiro: Editora FGV, 2006.

SABOURIN, E. Agricultores do Brasil, entre a troca mercantil e a reciprocidade. Rio de Janeiro: Editora Garamond Universitaria, Col. Terra Mater, 2009.

SCOTT, J. Weapons of the Weak: everyday forms of peasant resistance. Yale University Press: New Haven and London, 1985.

SILVA, M. G. Políticas públicas de desenvolvimento rural e organizações de agricultura familiar no município de Espera Feliz-MG. 2010. 127f. Dissertação (Mestrado em Extensão Rural) - Universidade Federal de Viçosa, MG, 2010.

SIMÕES, M. J. Política e tecnologia. Tecnologias da Informação e da comunicação e participação política em Portugal. Oeiras: Editora Celta, 2005.

SIMÕES, M. J.; LAS HERAS, S. Gênero e tecnologia da informação e da comunicação nos espaços domésticos: não chega ter, é preciso saber, querer e poder usar. Configurações. Revista de Sociologia, n. 8, p. 155-174, 2011.

SINGER, P. Cooperativismo e sindicatos no Brasil. In: CUT BRASIL. Sindicalismo e economia solidária: reflexões sobre o projeto da CUT. São Paulo: CUT, 1999. p. 23-28.

SOUZA, M. de L. O. Participação em associação de pequenos produtores: dilemas de administração coletiva. 1995. 180f. Dissertação (Mestrado em Administração Agrícola) - Universidade Federal de Lavras, UFLA, MG, 1995.

WARSCHAUER, M. Tecnologia e incluso social. A exclusão digital em debate. São Paulo: Editora Senac, 2006.

WEBER, M. Economia e sociedade: fundamentos da sociologia compreensiva. V. 2. São Paulo: UNB, 2004. 